International Journal of Engineering \& Technology, 9(3) (2020) 630-635
International Journal of Engineering \& Technology
SPC
Website: www.sciencepubco.com/index.php/IJET
Research paper

\title{
On COVID-19 outburst and smart city/urban system connection: worldwide sharing of data principles with the collaboration of IoT devices and AI to help urban healthiness supervision and monitoring
}

\author{
Jahangir Jabbar ${ }^{1}{ }^{*}$, Hussain Mehmood ${ }^{1}$, Umaima Hafeez ${ }^{1}$, Hassaan Malik ${ }^{1,2}$, Humayun Salahuddin ${ }^{3}$ \\ ${ }^{1}$ Department of Computer Science, National College of Business Administration \& Economics, Multan, Pakistan \\ ${ }^{2}$ School of Systems and Technology, University of Management \& Technology, Lahore, Pakistan \\ ${ }^{3}$ Department of Computer Science, HITEC University Taxila, Pakistan \\ *Corresponding author E-mail: jahangir2002@hotmail.com
}

\begin{abstract}
Every one of us knows about the rise of Coronavirus (COVID-19) from Wuhan (China) and its effects into nearby states and further motherlands, increased domestic and worldwide methods are being occupied to contain the outburst. In terms of Economic and Social point of view, it directly disturbs the metropolitan markets on a high level by engaging all the capitals and towns in a lock-down situation. It's also highlighted if this situation increases in different countries then it can lead in a direction to world-wide health disaster and in many accommodations as well. Be that as it may, while compelling conventions concerning the sharing of good information is underscored, urban information, then again, explicitly identifying with urban well-being and safe city ideas, is still seen from a patriot point of view as exclusively profiting a country's economy and its monetary and political impact. This article will explore the new and better universal understandings and also shows how smart city/urban systems be able to improve uniform procedures for bigger data sharing in the time of tragedies.
\end{abstract}

Keywords: COVID-19; Internet of Things (IoT); Smart Cities; Urban/Metropolitan Health; Artificial Intelligence; Coronavirus; Diseases.

\section{Introduction}

The Novel Corona-virus (COVID-19) is leading to shut down almost all cities in China, and triggering severe actions to be occupied in many others too. In Wuhan (China), due to this virus all the departmental stores, institutions and markets were totally closed [1]. Many other places were highlighted and are on high alert where the virus was reported although they are far from China. Taking in consideration about the spreading of virus, some protective actions were taken in Beijing, Hubei area and in Hong-Kong to make sure that the spreading of virus should be reduced and also to collect precise data on the virus [2].

In the last week of January 2020, World Health Organization has declared a "Global Public Health Emergency". This emergency was declared due to the high rate of virus spreading but World Health Organization also made a firm decision that not to announce this as a PHEIC - "Public Health Emergency of International Concern". Basically the purpose of PHEIC is to establish an occasion for community health risk to other countries through global spread of disease and it also needs a synchronized global response. A PHEIC scope may comprise: unexpected, severe, surprising or rare, brings effects for public health away from the affected State's nationwide border and may involve instant global action [3]. On the topic of Corona Virus with the help of Chinese experts, a worldwide edge was taken by distributing all influenza information on a platform known as GISAID [4]. With the help of this policy, many experts from different areas were having every single piece of information and also they are able to work much efficiently than before. A Test Center that's situated in Australia and is having a Virus Identification Lab also getting the data on viruses shared by the Chinese experts [5]. The issue of Corona Virus and its blowouts has given a chance for an interesting case study of urban health's conditions. All around the world there are different labs that are working on how to work collaboratively, how to share the data, how to prevent from virus and parallely Smart City Experts are also performing some efforts on how collaborative plans can be sanctioned for the maximum outputs on community if situation gets worst due to COVID-19. By using IoT devices, thermal camera and all previous negotiations there can be a better administration for these type of situations in case of upcoming possible out bursts and also to recover the stuff of health commonly [6] [7]. In situation of COVID-19, the only use of thermal cameras are not enough for the recognition of pandemics but combining these types of products with Artificial Intelligence technique can produce some accurate results or assistance. In case of COVID-19, early testing of infection is being followed at 
meeting halls, railway station and at airports. Collection of this health database from different technical products can easily support to get more reliable, precise and well organized information on out-breaks and their spreading [8]. If various smart city/urban system products are formed to support suitable rules that should give access for smooth communication then all the enhancements that is discussed earlier in the health-care area can only be attained. The suggestion [9] about the use of IoT sensors must fulfill the requirements of open procedures and at the similar spell the provider of device make it sure that all data must be integrated and safe throughout the time of transmission. Many of the smart city equipment's only use patented results that can only understandable by the providers but unluckily this wasn't the solution [10]. This issue was this that this condition usually generates needless points of information by translating incomplete or limited integrated assessments on the dynamics of urban empire. On the dynamics of Urban Empire, this condition usually generates needless points of information by translating limited integrated assessments. City Managers can't successfully take decisions to contain outbreaks and sufficiently act without cooperating the societal integrity of their city because of the limited information on growing drifts. This article will explore the significance of finding the standards of transmission between smart city/urban system and how urban ease can be attained more.

\section{Literature review}

\subsection{On the predictions of urban/metropolitan health statistics}

An extensive growth in the collection of data is seen in different areas like Sports, fitness sectors, showbiz, environmental, transportation and many others with the passage of time and with the help of massive deployment of IOT hardware [11]. Taking this in consideration it is sure that before the end of year 2020 near about 2 thousand 3 hundred and fourteen Exa-Bytes of data will be produced world-wide from the health zone [12]. A recognition by the Stanford Drug that this increment has observed a comparative increase, particularly in the field of medical, because of the growth in sources of data that aren't restricted to clinical records [12]. Or maybe, the expansion is being supported by drawing upon a heap and expanding number of IoT brilliant gadgets, that are anticipated to exponentially build the worldwide medicinal services market to an estimation of more than USD $\$ 543.3$ billion by 2025 [13]. Though, it is understood that there is a prospective for the data arcade, problems like safety of data and distribution, information secrecy and compulsory requirements of health-care monitoring and management are critical among others. If we look at the existing cases of COVID-19 outbursts then this must be controlled with pure attention to avoid risking struggles that are by now in place to fight the disease. On First, in the meantime these cut across various nations, which are a piece of the worldwide network and have their exceptional laws and guidelines about problems referenced above, it is vital to watch them according to the direct of their source nation's laws and guidelines; henceforth, underlining the significance of progressing in the direction of not just the advancing of information through its use yet in addition the requirement for institutionalized and all around concurred conventions.

From a minor group of users/manipulators, there're blames building for the collection of data, supervision and ease of access and storage of data because of the importance of such data in advancing throughput, competency and developments in various sectors is highly praised. The last especially incorporates select ICT organizations that are additionally situated in explicit topographies [6] [14 - 17]. In 21 ${ }^{\text {st }}$ Era, all the above blames are justified because big data is realized as new Gold-Rush and restricting its access means increase of influence, higher financial revenues and control at different points to those who handles the data. In the conventional and commercial supremacy empires, these benefits with Big Data are visibly manipulating geo-political situations and there's a bigger race between authoritative economics to make it sure that they've the extreme control of Big Data. As a valid example is the measure of 'push and pull' that has emerged from Huawei's 5G web arranged rollout [18]. Many countries like the United States and some European countries that are the main supporters and performers in world-wide governmental, financial and health department are not in a favor of this rollout, disagreeing that it's a misleading method of collection confidential information under the excuse of surveillance because the final service offers extra ordinary methods to surge internet speed and hereby effect the controlling of Big Data. It becomes prominent after this that the problem of controlling and managing data by some of the particular companies with their rules of patriotism and that these work for their individual comfort as well as to facilitate the zones they are registered in. Most companies that are having large volume of data are situated in big countries that have the impact in terms of governmentally, health-wise and financially, thus geo-political problems are predicted on the technical aspect [15] [19] [20]. It's estimated that these states shall carry-on their work in the direction of their major idea as soon as possible because these economies are believed award-wining tokens on international platform. Similar methodology is used in the health area to support where serious or critical data can't be shared easily between different economies as it can be beneficial for others in competition economies, although various economies definitely cherish the maximum use of benefits from this type of data gathering.

\subsection{An advanced survey of the COVID-19 occurrence}

While discussing the social issues associated to nationalism there're other challenges that are included in the increase movement of persons world-wide that is being improved by reduced expenses and higher speed. But when it approaches to public health then these challenges are particularly more highlighted because the data gathered for health related issues is not only based on those who travels but also consists on local citizens. When talking about the improvement of a nation's health position, it gets principal to get information from different locals requiring unrestricted sharing of this information. In circumstances as the case of COVID-19 outbreak bullying the world-wide health atmosphere, sharing of such data is highlighted. In Wuhan (China), this virus was firstly reported and in nearly 3 weeks $300+$ cases were deep-rooted and after a few days, the total number of cases reported was 2014. Out of 2014 cases there were 684 confirmed cases and 29 cases were reported outside Wuhan (China). On $26^{\text {th }}$ of Jan, 2020 the death toll reached at 56 [21]. Countries including Japan, Vietnam, Taiwan, France, Singapore, South Korea and Japan has hit by the virus [22]. Although major states are acknowledged to ready themselves for the possible outbreak according to above discussed case but their health plans and rules seems to be separate from one another. Developments regarding working for a treatment and world-wide accepted strategy can take much time without an international cooperative approach. 


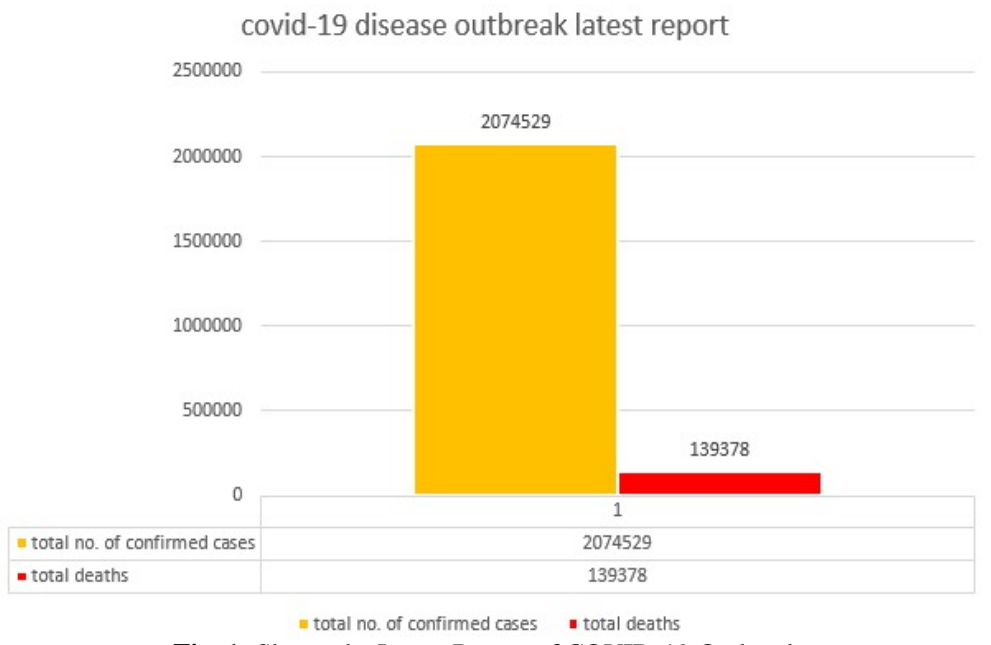

Fig. 1: Shows the Latest Report of COVID-19 Outbreak.

Due to the lack-ness of global collaboration, on $22^{\text {nd }}$ of Jan 2020 an emergency conference was held at Geneva by World Health Organization (WHO) to decide whether the outbreak of virus had grasped a level warranting global emergency fear. Protections measures adopted by China was appreciated by WHO, not like in 2002, when China caused delay and withhold the outbreak information for too long in addressing the epidemic [3]. This is the idea that's discussed in this article that it is not essential to conduct such a top level conference to result in action if there was unified sharing and accessing of data between various cities and because of this unified sharing of data, decisions can be made easily and earlier. To knob these challenges some international countries are not well equipped, posed by this kind of outburst for less information on problems like protective actions to be taken, signs of the virus, and the treatment procedures that a diseased person can easily be treated through among other matters and thus this is the miserable part. It was quite admirable when there's an appropriate response by the stake-holders in the regard to this outburst as related to preceding cases. Latter it includes "SARS" outbreak in the year 2002 and has taken an extensive time to detect and to deal with it [23]. Then in 2013, the outburst in West Africa named Ebola that also takes many months to detect and then the Zika Outburst addressed in 2014 before being effectively detected in 2015 . If discussed about COVID-19, it only took 17 days to be acknowledged.

Comparision between SARS(2002-3) and COVID-19

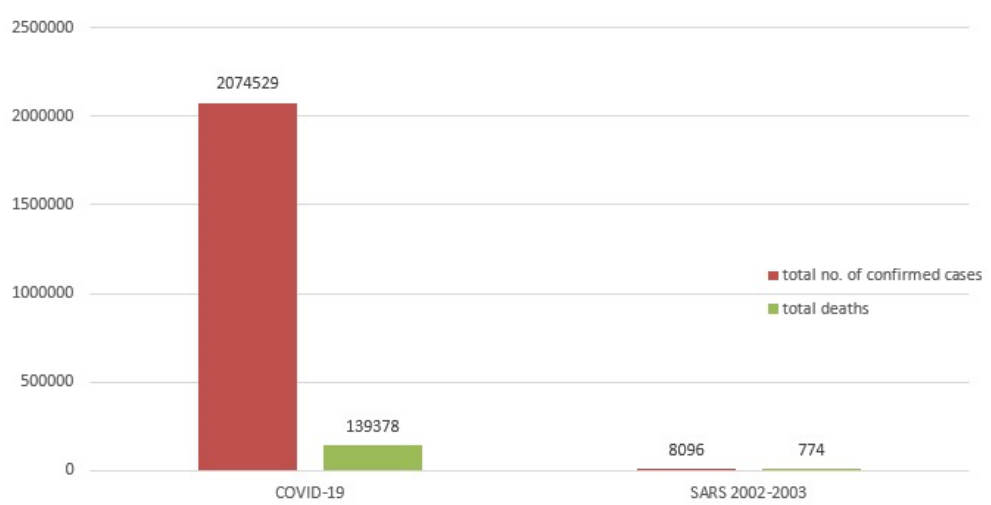

Fig. 2: Comparison between SARS and COVID-19.

A rapid detection of COVID-19 was possible after the virus genetic order was firstly discovered because the data sharing was also fast and immediate and this information makes Chinese experts much more able to share the same informative material with WHO and accordingly helpful in enabling and identification the auctioning of protective actions in other parts of the world. As compared to old epidemiological tactics that required months to detect the outburst type, now there're modern and up-to-date technical equipment that are allowed for the collection of data in real time environment [24]. In the same way, although all the significant data regarding virus has shared but there is some lack of important information [25] like the virus spreading from human to human and this is the major key to holding the disease as connections between humans from various parts of the world are still lively. To access a lot of data is also a challenge because the informative material is usually seen as sensitive for nationwide safety motives and for the economy as well.

\subsection{The urban/metropolitan security and economy}

Across the globe, there is a significant impact on local economies due to outbreak of any disease. Comparatively, in 2002 when SARS (severe Acute respiratory syndrome) (SARS) burst in China, it was approximated, there will be extra-ordinary negative effects provoke socially, economically, and health-wise, probably amounting between USD \$12-18 billion of Asian regional economy losses only from tourism, travel and retail sales [26]. The losses occurred due to the Zika virus outburst, dispersed by the daytime active Aides mosquitoes, are approximated in the affected areas between USD \$7 and USD \$18 billion as cost equator-belt economies [27]. In 2015, the approximated loss of USD \$2.2 billion caused by the Ebola virus (or Ebola hemorrhagic fever (EHF)) in GDP in three West African economies (Liberia, Guinea and Sierra) alone [28]. In regard to the present contagion of coronavirus, even though it is too immediate to calculate or propose its effects over the world economy, it is going to be suspected that, it can cause the instance of other outbursts where the loss of billions of dollars caused. The endowments of this intensifying loss can be endorsed in huge increased growth in travel bans being executed by some countries and their international airports, particularly and especially confining the people from going to the infected areas in China and 
increase within general non-Chinese transport movements. On this, observing that this virus outburst came very nearly on the celebrations of lunar New Year Eve, and that it had been predicted that more than 400 million people were proposed to fly in various parts of the world and China to enjoy this mega event, lots of the people have to rescheduled their preferences as to flights. Accommodations and events of entertainment due to the cancellations by the service provider [29]. All those people who had booked their flights before may get the invested money back following the rules by Chinese Civil Aviation Administration, although, this step has earlier overwhelmed the share stock value of the Airline Companies of China [29].

The above impressions manifest that the problems occurred by the outbreaks of virus outstrip the urban safety and effects all over the other features of our urban fabric. That's why, it turns into a preeminent to assure that the efforts taken to enclose a virus outstrips the agendas of nationalist where information and data transferring is usually prohibited, to a most universal agenda where mankind and universal sequences are inspirited. In order to ensure more economic stability, better monitoring and arising health threats, it would be easier to transfer global health data across the universe using the above approach, so that assuring no interruptions of other sectors such as tourism and flying industries, surrounded by others. This has become possible by assuring the shared, and dedicated efforts to control the outburst transmission and thus, movements of humans. This effort may remove uneasiness on flyers and may contains some positive aspects on the flying industries of tourism, which has been noticed to experience the huge economic loss after the occurrence of such outbreaks. This can be accomplished by assuring that data sharing protocols will be adjust to remove all the obstacles referring to information sharing. In this [30] hypothesize that such problems such as transparency, shortness of time for the sharing, approach and data quality, should be maintained so that the non-stop analyzing and computation can be seek.

\subsection{Data distribution and normalization with the help of smart city system}

In recent years the virus outburst have revealed that, from the diversified places the data inclusive of data of health can be derived. Now a days, in Coronavirus (COVID-19) case outburst, through monitoring and screening the data has been gathered from airports, by using smart sensing devices which are being installed in the premises of airports and also from personal workings in all the airports seaports. Such as, in the USA it has been noted that, at the 20 diverse airports monitoring is being occurred to figure out the feasible virus affected people seized for isolation at entry points. Verging on airports, [2], for more medical attention data and information about the virus positive patients is also being gathered from market places, restaurants like subways, health centers and bus terminals in Wuhan. Being in ascendancy specifically in China, and alternate regions of Asia where the confirmed cases of the COVID-19 have recorded. Using all these methods, alternate smart city sources of data contains the terminal tracking technology that are most of the time spotlighted in the concepts of Safe City, where, at entry point or exit, related data is gathered and investigated. [31] focal points that sensing devices connected in such suspected locations have much power to collect and transfer real-time data to digital framework inside the network, and the interconnections of devices inside the network makes them immensely much dedicated and powerful in showing updates of real-time over various issues. City areas are also famous for having various sensing devices for Urban Health, humans wears some of them. Although, all of them are not especially designed to record the present virus outburst case, they are eligible to record other relative parameters such as blood pressure, heart-beat, temperature of body and many more variables that offer necessary insights when investigated. [32], recognize these sensing devices for their performance in changing the sector of health care specifically by permitting for Connected Health $(\mathrm{CH})$ care, in which data gathered from these devices can be investigated and given out the observational information on the scenario of health in selected area. [33], moreover high points how appearing features like spatiotemporal mapping, management, remote monitoring and updated cloud computing efficiencies can radiate from such undertakes, rising towards the improved positive potential of urban management.

While the facts demonstrate that fundamental wellspring of medical data universally collected from common medical laboratories__ an evidence that has also been declared in the current epidemic case_this written content prospects that how the data collected from urban perspective can take a part to medical field. The sentiment to reside in this composition on the urban dimension is positioned on the truth that the present epidemic (COVID-19) is spreaded hugely from person-to-person contact, and in many cases, specifically where the spread is recorded in diverse countries, the initial point of contact is an city populated area, where large group of people travel using transport services, such as subway stations and airports. In various cases, these facilities, which are generally situated in urban territories, are noticed to have many supervision technologies installed to assure that if someone has demonstrating any symptoms of this viral disease are recognized and isolated. Although, even in comparable cases, as highlighted in current composition, the need for medical data is highlighted to assure that the use of present technologies across various geographies doesn't crack security requirements and data privacy. In this case, narrative technologies such as quantum cryptography and Block-Chain can assist in the consideration and be contrived to combine with data gathering technologies. This would results in the rapid growth of data from both the operators of Smart City and medical field, while it assures the privacy and security, however, assisting in giving out the relative information for improved informed decisions. Although, in spite of the unquestionable jobs that introduced gadgets play in giving relative health information, their data interchange facet requires to be rechecked. Initially the intercommunication are identified to a limited geography, so that they occasionally grow or intercommunicate with devices like them installed outside their own network. After this, these devices are commonly sourced and established by various corporations that uphold unique and special standards for data processing and transferring, and subsequently, the shackling cities to the sole utilization of their items. These procedures are adapted as non-governmental corporations attempt to boost their monetary additions, since the advanced arrangement market is a worthwhile one and is required to keep developing and extending [6] [7]. For its present application, the protocols standardizations as explained in this composition required to be seek to assure that there is logical transferring of data and information. It is suspected that by doing this problems such as data collecting burdens, accuracy and other complexities that have been faced (when systems are disintegrated) are decreased or disqualify altogether. The levelness can be achieved by, such as assuring that all the systems and devices are connected to same single network, such as performed in US, where all healthcare surveillance were collectively connected into National Healthcare Safety Network (NGSN) [34]. The storyline is that the urban areas are rapidly growing tuning on the Smart City Concept and increasing up an expanded adoption ratio of technological and interconnected items, present networks of surveillance can be calibrated again to form the use of those new databases sets. Convenient protocols although have to be prepared to assure impassive actions while assuring the security and privacy of people and data. With schemes like the current Coronavirus (COVID19) outburst, that not only effect upon the monetary conditions of urban areas, but also influence their social existing, it becomes essential to highlight the adaption of global standards for the sharing of data. Such a step could have distant encompassing effect over urban areas specifically in positively resist outburst and mishaps in safer, standardized and quicker way, such that when the solution is discovered, the outcomes can be simulated in multiple parts of the universe. With a cooperative protocol of data sharing, it can be possible to have huge dataset resulting in enhanced processing capabilities especially with technologies that are energized by tools of Artificial intelligence (AI). Over this way, as recognized by [35] [36], it is conceivable to encourage early identification, accomplish better determination and provide improved city management decisions for enhanced potential for virus supervision. 
It is conceivable to encourage that the sharing of data and cooperation can be more beneficial during the Ebola outburst 2014 in West Africa where scientists, clinicians and health-workers in between other stakeholders from all over the world, combine worked openly and become able to enclose the outburst of this generic [37]. On this front [38] highlighted that standards of transparency and trust required to be rechecked and increased to encourage loose data sharing and generation. Such could prompt a considerably prior discovery of virus outbreaks future scenario and in enhanced healthful management of the same, beyond minimal compromise on city operations and on an Urban monetary. Moreover, in emergency cases such as present outburst of COVID-19 and some other emergency, the requirement for insights of constant practices and global healthcare instructions are preeminent. This would assure that general populace and healthcare professionals both are acknowledged, guarded and survive inside the suggested protocols. As recognized by WHO [39], the healthcare instructions and constant practices are updated to also assure that the risk of health in question is decreased together with its outcomes. In the present condition the technological enhancement, like instructions, and regulations are preeminent as they have power to bring to negative and positive outcomes. The level of this paper is to enhance that it makes it possible now to combine the technologies such as the use of smart sensing devices by using IoT network and devices that can be wearable by humans, from mobile apps and other devices the data can be shared by the users and also to help the users as an information with certified and accredited healthcare professionals, and in this case, improve the results for positive disciplinary and more policies and resilient protocols.

\section{Conclusion}

Day by Day as the world grows in its adoption of the smart city technical tools and its associated ideas, these tools must be ready or prepared to ensure the thematic of urban health and that livability scopes are provided satisfactory. In this regard, it is said that lack-ness of regulations between the providers of smart city technology is heading towards to a communication gap among the data forums and cities. In the situation of Corona virus outbursts this is resulting in a non-creative system because initial findings and administration of the same can become more and more reliant on the technical strength of smart cities. This article hereby emphasizes on the vital needs to work towards the normalization of rules and regulations for the communication of advanced smart city and the requirement to more democratize the technical scope of smart city to promote transparency and fairness among stake-holders by delivering best suitable assistance in the tragic situation.

\section{References}

[1] Allam, Z. How Cities and Architecture Respond to the Wuhan Coronavirus. Available online: https://www.archdaily.com/932840/how-cities-andarchitecture-respond-to-the-wuhan-coronavirus .

[2] Buckley, C.; May, T. Effects of Coronavirus Begin Echoing Far from Wuhan Epicenter. Available online: https://www.nytimes.com/2020/01/25/world/asia/china-wuhan-coronavirus.html .

[3] WHO. Statement on the Meeting of the International Health Regulations (2005) Emergency Committee Regarding the Outbreak of Novel Coronavirus (2019-ncov). online: https://www.who.int/news-room/detail/23-01-2020-statement-on-the-meeting-of-the-international-health-regulations(2005)-emergency-committee-regarding-the-outbreak-of-novel-coronavirus-(2019-ncov)

[4] Wang, C.; Horby, P.W.; Hayden, F.G.; Gao, G.F. A novel coronavirus outbreak of global health concern. Lancet 2020, 395, 470-473. [Google Scholar] [CrossRef]. https://doi.org/10.1016/S0140-6736(20)30185-9.

[5] Nature. Coronavirus Latest: Australian Lab First to Grow Virus outside China. Available online: https://www.nature.com/articles/d41586-02000154-w

[6] Allam, Z. Cities and the Digital Revolution: Aligning Technology and Humanity; Springer International Publishing: Cham, Switzerland, 2020. [Google Scholar]. https://doi.org/10.1007/978-3-030-29800-5.

[7] Allam, Z. Data as the new driving gears of urbanization. In Cities and the Digital Revolution: Aligning Technology and Humanity; Allam, Z., Ed.; Springer International Publishing: Cham, Switzerland, 2020; pp. 1-29. [Google Scholar]. https://doi.org/10.1007/978-3-030-29800-5.

[8] Kamel Boulos, M.N.; Peng, G.; VoPham, T. An overview of geoai applications in health and healthcare. Int. J. Health Geogr. 2019, 18, 7. [Google Scholar] [CrossRef] [PubMed]. https://doi.org/10.1186/s12942-019-0171-2.

[9] Weber, M.; Podnar Žarko, I. A regulatory view on smart city services. Sensors 2019, 19, 415. [Google Scholar] [CrossRef]. https://doi.org/10.3390/s19020415.

[10] Vermesan, O.; Friess, P. Internet of Things_From Research and Innovation to Market Deployment; River Publishers: Gistrup, Denmark, 2014. [Google Scholar].

[11] Allam, Z.; Tegally, H.; Thondoo, M. Redefining the use of big data in urban health for increased liveability in smart cities. Smart Cities 2019, 2 , 259-268. [Google Scholar] [CrossRef]. https://doi.org/10.3390/smartcities2020017.

[12] Stanford Medicine. Harnessing the Power of Data in Health; Stanford Medicine: Stanford, CA, USA, 2017. [Google Scholar].

[13] Grand View Research. Iot in Healthcare Market Worth $\$ 534.3$ Billion by 2025 | Carg 19.9\%. Available online: https://www.grandviewresearch.com/press-release/global-iot-in-healthcare-market .

[14] Allam, Z. Digital urban networks and social media. In Cities and the Digital Revolution: Aligning Technology and Humanity; Allam, Z., Ed.; Springer International Publishing: Cham, Switzerland, 2020; pp. 61-83. [Google Scholar]. https://doi.org/10.1007/978-3-030-29800-5.

[15] Allam, Z. The emergence of anti-privacy and control at the nexus between the concepts of safe city and smart city. Smart Cities 2019, 2, 96-105. [Google Scholar] [CrossRef]. https://doi.org/10.3390/smartcities2010007.

[16] Allam, Z. Contextualising the smart city for sustainability and inclusivity. New Des. Ideas 2018, 2, 124-127. [Google Scholar]

[17] Allam, Z.; Dhunny, Z.A. On big data, artificial intelligence and smart cities. Cities 2019, 89, 80-91. [Google Scholar] [CrossRef]. https://doi.org/10.1016/j.cities.2019.01.032.

[18] Kharpal, A. China 'has the Edge' in the War for $5 \mathrm{~g}$ and the $\mathrm{Us}$ and Europe Could Fall Behind. Available online: https://www.cnbc.com/2018/03/07/china-has-the-edge-in-the-war-for-5g-us-and-eu-could-fall-behind.html

[19] Allam, Z. Privatization and privacy in the digital city. In Cities and the Digital Revolution: Aligning Technology and Humanity; Allam, Z., Ed.; Springer International Publishing: Cham, Switzerland, 2020; pp. 85-106. [Google Scholar]. https://doi.org/10.1007/978-3-030-29800-5.

[20] Allam, Z. Theology, sustainability and big data. In Theology and Urban Sustainability; Allam, Z., Ed.; Springer International Publishing: Cham, Switzerland, 2020; pp. 53-67. [Google Scholar]. https://doi.org/10.1007/978-3-030-29673-5_4.

[21] WHO. Novel Coranvirus (2019-ncov) Situation Report; World Health Organisation: Geneva, Switzerland, 2020. [Google Scholar].

[22] Tierney, L.; Meko, T.; Fox, J. Mapping the Spread of the New Coronavirus. Available online: https://www.washingtonpost.com/world/2020/01/22/mapping-spread-new-coronavirus/?arc404=true .

[23] Ren, G. As Coronoavirus Outbreak Surges in China, Who Call for Emergency Meeting. Available online: https://www.healthpolicy-watch.org/ascoronavirus-outbreak-surges-in-china-who-calls-for-emergency-meeting/.

[24] Grubaugh, N. Rapid Data Sharing and Genomics Vital to China Virus Response. Available online: https://medicine.yale.edu/news-article/22389/.

[25] Wetsman, N. Rapid Global Response to the New Coronavirus Shows Progress Made Since Sars. Available online: https://www.theverge.com/2020/1/22/21077214/coronavirus-rapid-global-response-progress-sars-unknown-virus-china-public-health 
[26] Qiu, W.; Chu, C.; Mao, A.; Wu, J. The impacts on health, society, and economy of sars and h7n9 outbreaks in china: A case comparison study. J. Environ. Public Health 2018, 2018, 2710185. [Google Scholar] [CrossRef] [PubMed]. https://doi.org/10.1155/2018/2710185.

[27] Smith, K.M.; Machalaba, C.C.; Seifman, R.; Feferholtz, Y.; Karesh, W.B. Infectious disease and economics: The case for considering multi-sectoral impacts. One Health 2019, 7, 100080. [Google Scholar] [CrossRef] [PubMed]. https://doi.org/10.1016/j.onehlt.2018.100080.

[28] CDC. The Cost of the Ebola Epidemic. Available online: https://www.cdc.gov/vhf/ebola/history/2014-2016-outbreak/cost-of-ebola.html .

[29] BBC. China's Travel Industry Counts Cost of Coronavirus. Available online: https://www.bbc.com/news/business-51232374 .

[30] Lawpoolsri, S.; Kaewkungwal, J.; Khamsiriwatchara, A.; Sovann, L.; Sreng, B.; Phommasack, B.; Kitthiphong, V.; Lwin Nyein, S.; Win Myint, N.; Dang Vung, N.; et al. Data quality and timeliness of outbreak reporting system among countries in greater mekong subregion: Challenges for international data sharing. PLoS Negl. Trop. Dis. 2018, 12, e0006425. [Google Scholar] [CrossRef] [PubMed]. https://doi.org/10.1371/journal.pntd.0006425.

[31] Li, W.; Batty, M.; Goodchild, M.F. Real-time gis for smart cities. Int. J. Geogr. Inf. Sci. 2020, 34, 311-324. [Google Scholar] [CrossRef]. https://doi.org/10.1080/13658816.2019.1673397.

[32] Loncar-Turukalo, T.; Zdravevski, E.; Machado da Silva, J.; Chouvarda, I.; Trajkovik, V. Literature on wearable technology for connected health: Scoping review of research trends, advances, and barriers. J. Med. Internet Res. 2019, 21, e14017. [Google Scholar] [CrossRef] [PubMed] https://doi.org/10.2196/14017.

[33] Vashist, S.K.; Luppa, P.B.; Yeo, L.Y.; Ozcan, A.; Luong, J.H.T. Emerging technologies for next-generation point-of-care testing. Trends Biotechnol. 2015, 33, 692-705. [Google Scholar] [CrossRef] [PubMed]. https://doi.org/10.1016/j.tibtech.2015.09.001.

[34] Tokars, J.I.; Richards, C.; Andrus, M.; Klevens, M.; Curtis, A.; Horan, T.; Jernigan, J.; Cardo, D. The changing face of surveillance for health careassociated infections. Clin. Infect. Dis. 2004, 39, 1347-1352. [Google Scholar] [CrossRef] [PubMed]. https://doi.org/10.1086/425000.

[35] Jiang, F.; Jiang, Y.; Zhi, H.; Dong, Y.; Li, H.; Ma, S.; Wang, Y.; Dong, Q.; Shen, H.; Wang, Y. Artificial intelligence in healthcare: Past, present and future. Stroke Vasc. Neurol. 2017, 2, 230. [Google Scholar] [CrossRef] [PubMed]. https://doi.org/10.1136/svn-2017-000101.

[36] Allam, Z. Achieving neuroplasticity in artificial neural networks through smart cities. Smart Cities 2019, 2, 118-134. [Google Scholar] [CrossRef]. https://doi.org/10.3390/smartcities2020009.

[37] Bockarie, M.J. Sharing Data can Help Prevent Public Health Emergencies in Africa. Available online: https://theconversation.com/sharing-data-canhelp-prevent-public-health-emergencies-in-africa-119672.

[38] Boué, S.; Byrne, M.; Hayes, A.W.; Hoeng, J.; Peitsch, M.C. Embracing transparency through data sharing. Int. J. Toxicol. $2018,37,466-471$. [Google Scholar] [CrossRef] [PubMed]. https://doi.org/10.1177/1091581818803880.

[39] WHO. Health Emergency and Disaster Risk Management Framework; World Health Organization: Geneva, Switzerland, 2019. [Google Scholar]. 